\section{On the colors seen in achromatic patterns}

\author{
N. J. WADE \\ University of Dundee, Dundee DDI 4HN, Scotland
}

and

R. H. DAY

Monash University, Clayton, Victoria 3168, Australia

There has been considerable curiosity about the subjective colors seen in achromatic patterns since Brewster's description of them in 1825 (see Cohen \& Gordon, 1949, Erb \& Dallenbach, 1939, and Wade 1977a for their history). Typically, the colors seen in stationary patterns are unsaturated reds, yellows, greens, and blues. These are associated with a scintillation or streaming over the pattern, like shimmering dots often moving perpendicularly to the contours. The basis for these color effects and those with moving patterns would seem to lie in the temporal modulation of the input (see Piggins, Kingham, \& Holmes, 1972; Young, 1977).

Stanley and Hoffman (1976) have recently reported a somewhat different phenomenon in which pastel shades of particular colors are associated with specific contour orientations of a stationary pattern. With a pattern similar to that in Figure 1, most of their subjects reported that the spaces between the vertical lines appeared reddish-pink and those between the horizontal lines greenish-blue. The effect was tied to the spatial coordinates of the eye, since the gravitationally vertical elements of the patterns looked pale green when the head was inclined by $90^{\circ}$.

When we were observing a pattern with similar concentric squares (Figure 4 in Wade, 1978), the subjective colors we saw within particular sectors differed in both color and intensity. We then found that the colors disappeared when the pattern was viewed through a $1-\mathrm{mm}$ artificial pupil and that the color tied to a particular orientation could be changed by rotating a cylindrical lens before the eye. One of us has marked regular astigmatism, and it was he who experienced the colors more vividly. Thus, it would seem possible that the colors seen in patterns

This research was supported by a grant from the Medical Research Council to N. J. W. The assistance of the Commonwealth Universities Interchange scheme to R. H. D. is gratefully acknowledged. We thank Linda Wilson for her help in the collection and analysis of the data. Requests for reprints may be sent to: N. J. Wade, Department of Psychology, University of Dundee, Dundee DD1 4HN, Scotland.

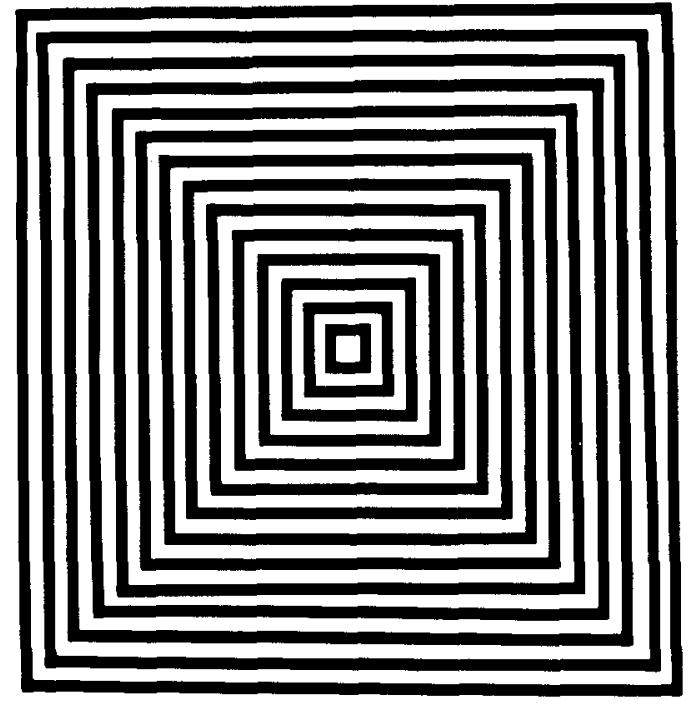

Figure 1. Concentric square pattern used in Experiments 1 and 2.

comprised of orthogonal contours result from the regular astigmatism of the eye. If this is so, then focusing the lines of one orientation would render the others blurred and the consequent chromatic aberration could yield the colors. Indeed, a figure essentially similar to that used by Stanley and Hoffman was introduced by Verhoeff (1899) as a test for regular astigmatism (see Figure 2).

Here we report two experiments which were designed to examine the hypothesis that color effects

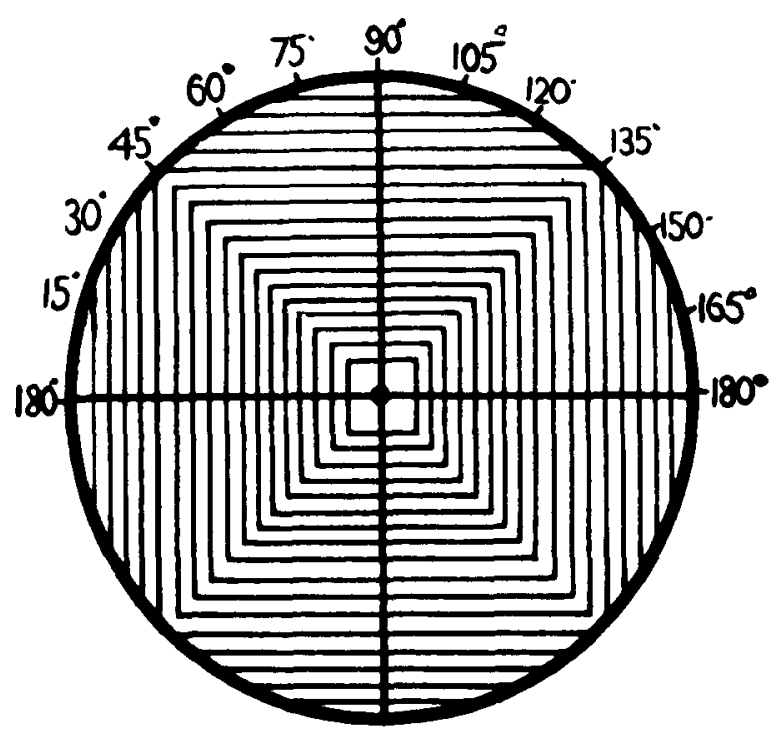

Figure 2. The astigmatic chart introduced by Verhoeff (1899), 
described by Stanley and Hoffman (1976) are due to astigmatism. The rationale for both experiments was simple: it was expected that subjects would report colors in those orientations blurred by their natural astigmatism and in those blurred by an interposed cylindrical lens.

\section{EXPERIMENT 1}

\section{Method}

Subjects. Twenty subjects took part in the experiment. All were given vision screening tests using a Keystone ophthalmic telebinocular.

Apparatus. The pattern consisted of concentric outline squares, as in Figure 1, made by attaching black tape to a white card. The pattern was illuminated by a projector and viewed against a dark background. The Michelson contrast was 0.75 . At the viewing distance of $145 \mathrm{~cm}$, the whole pattern subtended $15^{\circ}$ at the eye and each black line subtended 15' of arc. The subject's head was supported by a chin- and foreheadrest, and a lens-well was located in front of each eye.

Procedure. The vision screening included tests for astigmatism, using Lancaster-Regan-type astigmatic dials. Subjects then viewed the pattern with the unaided eye (even in those cases where an optical correction was usually worn) for approximately $1 \mathrm{~min}$, and reported the colors visible, if any. This was repeated with the pattern oriented vertically and at $45^{\circ}$, and for the left and right eyes separately. The procedure was repeated with a +2 -diopter cylindrical lens before the eye. Only the vertical orientation of the pattern was used in this second part, and the axis of the lens was aligned either vertically or horizontally.

\section{Results}

There were surprisingly few reports of colors seen in the pattern when using the naked eye. The reports from the subjects were analyzed, and the predominant color occurring, if any, was noted for each orientation and eye. The frequency of color reports is given in Table 1A. These showed little agreement with Stanley and Hoffman's results; verticals were not always pink, and nor were horizontals green. More- over, Stanley and Hoffman found that no colors were reported when the pattern was inclined at $45^{\circ}$; in this orientation, colors were seen with about the same frequency as when the pattern was vertical. Thus, the phenomenon is not as robust as their results suggested. The frequencies of color reports (irrespective of the particular color) in each of the four line orientations were analyzed by Cochran's Q test (Siegel, 1956), applied to the left and right eyes separately. The analysis yielded no significant differences between the four line orientations $(Q=5.4$ and $1.38, \mathrm{df}=3, \mathrm{p}>.05$, for the left and right eyes, respectively).

The number of subjects reporting colors can be increased by observing the pattern through a cylindrical lens, as is shown in Table 1B. However, the colors are more frequently confined to the contour orientation blurred by the lens. For example, with the axis of the lens vertical, the vertical lines are blurred but the horizontal lines remain in focus. The differences between the frequencies of color reports in the four line orientations were significant $(Q=28.7$ and 20.2 , df $=3, p<.001$ for the left and right eyes, respectively). The more frequent occurrence of subjective colors in those parts of the pattern that are out of focus lends support to the hypothesis that blurring due to astigmatism with consequent chromatic aberration is the basis of the effect.

\section{EXPERIMENT 2}

\section{Method}

This experiment was essentially similar to the previous one, except that the viewing distance was doubled $(290 \mathrm{~cm})$ so that the pattern subtended $7.5^{\circ}$ and the lines $7.5^{\prime}$ of arc, and the power of the cylindrical lens was halved ( +1 diopter). This change was based on the informal observation that the effect appeared stronger at the increased viewing distance. Twenty subjects were tested.

Table 1

Number of Subjects Reporting Orientation-Specific Subjective Colors in a Concentric Square Pattern (Experiment 1)

\begin{tabular}{|c|c|c|c|c|c|c|c|c|c|c|c|c|c|c|c|c|}
\hline \multirow{6}{*}{$\begin{array}{c}\text { Colors } \\
\text { Reported }\end{array}$} & \multicolumn{8}{|c|}{ (A) Normal viewing } & \multicolumn{8}{|c|}{$\begin{array}{c}\text { (B) With }+2 \text {-diopter cylindrical lens, } \\
\text { pattern vertical }\end{array}$} \\
\hline & \multirow{2}{*}{\multicolumn{4}{|c|}{$\frac{\text { Left Eye Used }}{\text { Pattern Orientation }}$}} & \multicolumn{4}{|c|}{ Right Eye Used } & \multicolumn{4}{|c|}{ Left Eye Used } & \multicolumn{4}{|c|}{ Right Eye Used } \\
\hline & & & & & \multicolumn{4}{|c|}{ Pattern Orientation } & \multicolumn{4}{|c|}{ Lens Axis } & \multicolumn{4}{|c|}{ Lens Axis } \\
\hline & \multicolumn{2}{|c|}{ V } & \multicolumn{2}{|c|}{45} & \multicolumn{2}{|c|}{ V } & \multicolumn{2}{|c|}{45} & \multicolumn{2}{|c|}{ V } & \multicolumn{2}{|c|}{ H } & \multicolumn{2}{|c|}{ V } & \multicolumn{2}{|c|}{$\mathbf{H}$} \\
\hline & \multicolumn{2}{|c|}{$\underset{\text { Orientation }}{\text { Line }}$} & \multicolumn{2}{|c|}{$\begin{array}{c}\text { Line } \\
\text { Orientation }\end{array}$} & \multicolumn{2}{|c|}{$\begin{array}{c}\text { Line } \\
\text { Orientation }\end{array}$} & \multicolumn{2}{|c|}{$\begin{array}{c}\text { Line } \\
\text { Orientation }\end{array}$} & \multicolumn{2}{|c|}{$\begin{array}{c}\text { Line } \\
\text { Orientation }\end{array}$} & \multicolumn{2}{|c|}{$\begin{array}{c}\text { Line } \\
\text { Orientation }\end{array}$} & \multicolumn{2}{|c|}{$\begin{array}{c}\text { Line } \\
\text { Orientation }\end{array}$} & \multicolumn{2}{|c|}{$\begin{array}{c}\text { Line } \\
\text { Orientation }\end{array}$} \\
\hline & V & $\mathrm{H}$ & $\mathrm{TL}$ & TR & V & $\mathrm{H}$ & TL & TR & V & $\mathrm{H}$ & V & $\mathbf{H}$ & V & $\mathbf{H}$ & V & $\mathrm{H}$ \\
\hline Red/Pink & 2 & 1 & 2 & & & 1 & & 1 & 4 & 1 & 1 & 4 & 2 & 1 & & 3 \\
\hline Orange/Yellow & & & 2 & 2 & 2 & 1 & 1 & 1 & 1 & & & 1 & 1 & & & 3 \\
\hline Green/Blue & 1 & 3 & 3 & 3 & 4 & 4 & 4 & 2 & 8 & 3 & & 11 & 11 & 3 & 4 & 6 \\
\hline Purple/Brown & 1 & & & 1 & 1 & & & 1 & & & & & & & & 1 \\
\hline Total & 4 & 4 & 7 & 6 & 7 & 6 & 5 & 5 & 13 & 4 & 1 & 16 & 14 & 4 & 4 & 13 \\
\hline
\end{tabular}

Note-V signifies vertical; $H$, horizontal; $T L$, top of line left; $T R$, top of line right. 
Table 2

Number of Subjects Reporting Orientation-Specific Subjective Colors in a Concentric Square Pattern (Experiment 2)

\begin{tabular}{|c|c|c|c|c|c|c|c|c|c|c|c|c|c|c|c|c|}
\hline & \multicolumn{8}{|c|}{ (A) Normal viewing } & \multicolumn{8}{|c|}{$\begin{array}{c}\text { (B) With }+1 \text {-diopter cylindrical lens, } \\
\text { pattern vertical }\end{array}$} \\
\hline & \multicolumn{4}{|c|}{ Left Eye Used } & \multicolumn{4}{|c|}{ Right Eye Used } & \multicolumn{4}{|c|}{ Left Eye Used } & \multicolumn{4}{|c|}{ Right Eye Used } \\
\hline & \multicolumn{4}{|c|}{ Pattern Orientation } & \multicolumn{4}{|c|}{ Pattern Orientation } & \multicolumn{4}{|c|}{ Lens Axis } & \multicolumn{4}{|c|}{ Lens Axis } \\
\hline \multirow{3}{*}{$\begin{array}{c}\text { Colors } \\
\text { Reported }\end{array}$} & \multicolumn{2}{|c|}{$\mathrm{V}$} & \multicolumn{2}{|c|}{45} & \multicolumn{2}{|c|}{$\mathrm{V}$} & \multicolumn{2}{|c|}{45} & \multicolumn{2}{|c|}{ V } & \multicolumn{2}{|c|}{$\mathrm{H}$} & \multicolumn{2}{|c|}{$v$} & \multicolumn{2}{|c|}{$\mathrm{H}$} \\
\hline & \multicolumn{2}{|c|}{$\begin{array}{c}\text { Line } \\
\text { Orientation }\end{array}$} & \multicolumn{2}{|c|}{$\underset{\text { Line }}{\text { Orientation }}$} & \multicolumn{2}{|c|}{$\underset{\text { Orientation }}{\text { Line }}$} & \multicolumn{2}{|c|}{$\begin{array}{c}\text { Line } \\
\text { Orientation }\end{array}$} & \multicolumn{2}{|c|}{$\begin{array}{c}\text { Line } \\
\text { Orientation }\end{array}$} & \multicolumn{2}{|c|}{$\begin{array}{c}\text { Line } \\
\text { Orientation }\end{array}$} & \multicolumn{2}{|c|}{$\begin{array}{c}\text { Line } \\
\text { Orientation }\end{array}$} & \multicolumn{2}{|c|}{$\begin{array}{c}\text { Line } \\
\text { Orientation }\end{array}$} \\
\hline & $\mathrm{V}$ & $\mathrm{H}$ & TL & TR & V & $H$ & TL & TR & V & $\mathrm{H}$ & $\mathrm{V}$ & $\mathbf{H}$ & $\mathrm{V}$ & $\mathrm{H}$ & V & $\mathrm{H}$ \\
\hline Red/Pink & 2 & 4 & 1 & 2 & 3 & 4 & 1 & 3 & 2 & 1 & 2 & 1 & 4 & & 2 & 4 \\
\hline Orange/Yellow & & & 1 & 2 & & 1 & & & & & & 2 & 1 & & & \\
\hline Green/Blue & 2 & 1 & 1 & 1 & 3 & 1 & & 1 & 9 & & 2 & 3 & 3 & & 1 & 5 \\
\hline Purple/Brown & 2 & & 2 & 1 & 2 & 1 & 4 & 2 & 1 & 1 & 1 & 3 & & 1 & 1 & 3 \\
\hline Total & 6 & 5 & 5 & 6 & 8 & 7 & 5 & 6 & 12 & 2 & 5 & 9 & 8 & 1 & 4 & 12 \\
\hline
\end{tabular}

Note-V signifies vertical; $H$, horizontal; $T L$, top of line left; $T R$, top of line right.

\section{Results}

The frequency of color reports is given in Table 2. Again, each entry refers to the predominant color, if any, seen by a subject. Under unaided viewing conditions (Table $2 \mathrm{~A}$ ), less than half the subjects reported colors, and these were not related consistently to particular line orientations $(Q=3.0$ and 2.8 , $\mathrm{df}=3, \mathrm{p}>.05$, for the left and right eyes, respectively). Placing a +1 -diopter cylindrical lens in front of one eye again increased the reports of colors, but only for the orientations in which the images were blurred $(\mathrm{Q}=7.61$ and 15.0, $\mathrm{df}=3, \mathrm{p}<.05$ and $\mathrm{p}<.005$, for the left and right eyes, respectively). The results provide general support for those of Experiment 1 , although fewer subjects reported lensinduced color. Thus, colors are more frequently associated with orientations that are out of focus, but there appears to be little relation between the particular colors reported and the orientation of the lines during normal viewing.

\section{DISCUSSION}

Observing patterns comprised of orthogonal contours can generate subjective colors which are relatively uniform, and so distinguishable from the Brewster-type subject colors seen in line patterns. ${ }^{1}$ The effect does not seem to be as clear-cut or robust as is suggested by Stanley and Hoffman's data: less than half the subjects reported such uniform colors when viewing the pattern with the unaided eye. In order to gain an impression of the generality of the effect, a slide of Figure 1 was presented to a class of 100 students. They viewed the pattern using the sighting dominant eye and scored a checklist of color names (including a None category) separately for the vertical and horizontal line orientations. Less than half the subjects reported seeing colors at all, and of those who did the predominant color was green, irrespective of line orientation.

Most of the subjects tested in the experiments exhibited slight regular astigmatism, as would be expected (see Duke-Elder, 1970), but those reporting the colors were not markedly different from the others with regard to their astigmatism. Rendering the pattern unequal in clarity by viewing it through a cylindrical lens increased the frequency of color reports, and the colors were associated mostly with the contours that were blurred. This occurred in both experiments, and it lends support to the hypothesis that the colors seen in such patterns are due to blur-induced chromatic aberration.

It would seem prudent to examine hypotheses based on the optical properties of the eye before relating the effect to others that are probably a consequence of the functioning of orientation-sensitive cells in the visual cortex, as Stanley and Hoffman (1976) have done.

\section{REFERENCES}

Brewster, D. On some remarkable affections of the retina, as exhibited in its insensibility to indirect impressions, and to the impressions of attenuated light. Edinburgh Journal of Science, 1825, 3, 288-293.

Conen, J., \& Gordon, D. A. The Prevost-Fechner-Benham subjective colors. Psychologicul Bulletin, 1949, 6, 97-136.

DuKE-ELder, S. System of ophthalmology (Vol. V). Ophthalmic optics and refraction. London: Kimpton. 1970.

Erb, M. B.. \& Dallenbach, K. M. "Subjective" colors from line-patterns. American Journal of Psychology, 1939, 52, 227.241

Piggins. D. J., Kingham, J. R., \& Holmes, S. M. Colour, colour saturation, and pattern induced by intermittent illumination: An initial study. British Journal of Physiological Optics, 1972, 27, 120-125.

SIEGEL, S. Nonparametric statistics for the behavioral sciences. New York: McGraw-Hill. 1956. 
Stanley, G., \& Hoffman, W. C. Orientation-specific color effects without adaptation. Bulletin of the Psychonomic Society, 1976, 7. 513-514.

VerhoefF, F. H. Two new astigmatic charts. Ophthalmic Record, 1899, 8, 541-544.

$\mathrm{W}_{\mathrm{ADE}}, \mathrm{N}$. J. A note on the discovery of subjective colours. Vision Research, 1977, 17, 671-672. (a)

W ADE, N. J. Distortions and disappearances of geometrical patterns, Perception, 1977, 6, 407-433. (b)

WAdE, N. J. Op art and visual perception. Perception, 1978, 7, 21-46.

Young, R. A. Some observations on temporal coding of color vision: Psychophysical results. Vision Research, 1977, 17, 957-965.

\section{NOTE}

1. The reports contained references to streaming colored dots as well as pattern distortions (see Wade, 1977b), but these were disregarded in the present analysis.

(Received for publication December 8, 1977.) 